\title{
Development of a Portable Single Photon Ionization-Photoelectron Ionization Time-of-Flight Mass Spectrometer
}

\author{
Yunguang Huang, ${ }^{1}$ Jinxu Li, ${ }^{2}$ Bin Tang, ${ }^{1}$ Liping $\mathrm{Zhu},{ }^{1}$ Keyong $\mathrm{Hou}^{2}$ and Haiyang $\mathrm{Li}^{2}$ \\ ${ }^{1}$ Electric Power Research Institute, Guangxi Power Grid Corporation, Nanning 530023, China \\ ${ }^{2}$ Key Laboratory of Separation Science for Analytical Chemistry, Dalian Institute of Chemical Physics, Chinese Academy of Sciences, \\ Dalian 116023, China
}

Correspondence should be addressed to Bin Tang; catkingtb@aliyun.com

Received 10 July 2015; Revised 29 September 2015; Accepted 30 September 2015

Academic Editor: Frantisek Foret

Copyright (C) 2015 Yunguang Huang et al. This is an open access article distributed under the Creative Commons Attribution License, which permits unrestricted use, distribution, and reproduction in any medium, provided the original work is properly cited.

\begin{abstract}
A vacuum ultraviolet lamp based single photon ionization- (SPI-) photoelectron ionization (PEI) portable reflecting time-of-flight mass spectrometer (TOFMS) was designed for online monitoring gas samples. It has a dual mode ionization source: SPI for analyte with ionization energy (IE) below $10.6 \mathrm{eV}$ and PEI for IE higher than $10.6 \mathrm{eV}$. Two kinds of sampling inlets, a capillary inlet and a membrane inlet, are utilized for high concentration and trace volatile organic compounds, respectively. A mass resolution of 1100 at $\mathrm{m} / z 64$ has been obtained with a total size of $40 \times 31 \times 29 \mathrm{~cm}$, the weight is $27 \mathrm{~kg}$, and the power consumption is only $70 \mathrm{~W}$. A mixture of benzene, toluene, and xylene (BTX), $\mathrm{SO}_{2}$, and discharging products of $\mathrm{SF}_{6}$ were used to test its performance, and the result showed that the limit of quantitation for BTX is as low as $5 \mathrm{ppbv}(S / N=10: 1)$ with linear dynamic ranges greater than four orders of magnitude. The portable TOFMS was also evaluated by analyzing volatile organic compounds from wine and decomposition products of $\mathrm{SF}_{6}$ inside of a gas-insulated switchgear.
\end{abstract}

\section{Introduction}

Mass spectrometry has been widely employed for detection of environmental pollutants, illegal drugs, and explosives for its rapid, high sensitivity, and accuracy in qualitative analysis [1]. However, traditional mass spectrometry used in lab can barely be applied for in situ detection due to its size and weight. The technology of portable mass spectrometry has been recognized as one of the most promising and widely used techniques in environment monitoring, field diagnosis, and process monitoring.

Researches on miniaturization of magnetic mass spectrometry, quadrupole mass spectrometry, ion trap mass spectrometry, and time-of-flight mass spectrometry (TOFMS) all have been reported in the literature [2-8]. Compared with other types of mass spectrometry, TOFMS provides rapid scanning speed, full range scanning of the mass to charge, and simpleness in structure. Particularly, TOFMS can give a satisfying performance with moderate mechanical accuracy. Hopkins et al. have achieved remarkable approaches in developing and application of field detecting TOFMS [9-11]. A tiny TOFMS analyzer was developed with a length of $20 \mathrm{~cm}$ and $500 \mathrm{~g}$ in weight. A coaxial reflecting TOFMS with MALDI ion source was also developed, and the mass range is as high as $10,000 \mathrm{~m} / z$; sensitivity of picomole and resolution of 300-1000 $(\mathrm{m} / \Delta \mathrm{m})$ were achieved. Cornish and Cotter [12] designed an end cap miniature TOFMS, this TOFMS featured with a laser ion source and a resolution of 210 at $1061 \mathrm{~m} / \mathrm{z}$. Brinckerhoff et al. [13] explored a laser-focusing micro TOFMS with coaxial structure and a length of $20 \mathrm{~cm}$, and multifield energy focusing technique was applied to this micro TOFMS. The micro TOFMS has a resolution of $1000 \mathrm{~m} / \Delta m$ with an upper mass range to $1000 \mathrm{~m} / z$ and was used for elemental and organic analysis on the surface of a planet. White et al. developed a mini TOFMS with membrane inlet and EI ion source [14]. The mini TOFMS 

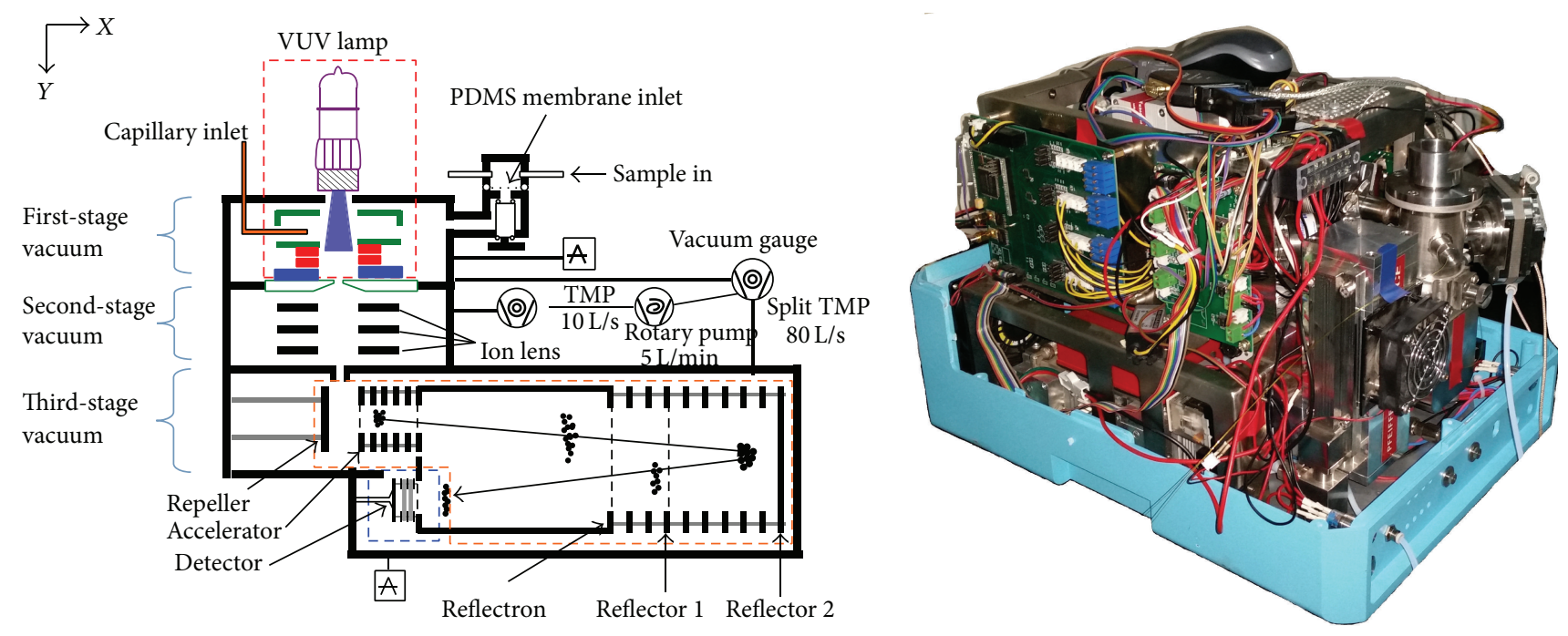

FIGURE 1: Schematic diagram and photograph of the portable time-of-flight mass spectrometer.

was $53 \times 33 \times 21 \mathrm{~cm}$ in size and $21 \mathrm{~kg}$ in weight with a resolution of 300 at $28 \mathrm{~m} / z$. The experiment data was well linear fitted in the range of $50-1200 \mathrm{ppb}$ for BTX. A portable TOFMS investigated by Syage et al. has a frequency of $200 \mathrm{~Hz}$ [15], and the limit of detection for aromatic compounds was 10-100 ppb with $10 \mathrm{~s}$ analysis time.

In situ portable TOFMS prefers soft ionization source for rapid spectrum interpretation. Due to the $70 \mathrm{eV}$ high energy electrons, a large number of ion fragments could be present with traditional electron ionization source, and the overlapping peaks from fragments ions would bring much trouble in spectrum interpretation. A VUV lamp is a type of soft ionization source, and the analyte molecules can be ionized through single photon ionization (SPI) with few fragments. The VUV lamp is compact and can be operated without chemical reagents. Therefore, the VUV lamp is very suitable for rapid in situ detection. Li et al. have been working on developing portable and miniature TOFMS with VUV lamp ever since 2002, such as SPI source with membrane inlet miniature TOFMS, magnetic enhanced photon ionization source TOFMS, single photon ionization combined with chemical ionization source TOFMS, and quasi-trapping chemical ionization source TOFMS [16-19]. Proton transfer reaction mass spectrometer (PTRMS) is another widely used soft ionization source for online measurements of trace components with concentrations as low as a few pptv, which is developed on the basis of proton transfer reactions with reactant ion of $\mathrm{H}_{3} \mathrm{O}^{+}$. But the PTR reaction is fulfilled at high pressure, and the vacuum system is much larger in the PTRMS, so it is very hard for the miniaturization with PTRMS [20, 21].

The unique characteristics of the present portable TOFMS compared to existing technologies are the combination of novel dual SPI/PEI ionization source, versatile sampling inlet, differential pumping for high gas throughput, and low-power consumption. The details of the operating conditions and the applications of the portable TOFMS were demonstrated in the following sections.

\section{Description of Spectrometer}

2.1. Instrument Description. A schematic diagram and photograph that illustrate the features of the portable TOFMS are presented in Figure 1. The dimensions of the TOFMS are $40 \times 31 \times 29 \mathrm{~cm}$, and it weighs about $27 \mathrm{~kg}$ including the battery and all the pumping system. Power consumption is approximately $70 \mathrm{~W}$ at working condition. The portable TOFMS consists of an ionization source, an orthogonal acceleration reflection mass analyzer, two sampling inlets, the pumping system, and the electronics for the TOFMS timing and data acquisition. The ions generated from ionization source are accelerated from the source region to orthogonal repelling region through a set of electrodes. The repeller then was applied with pulse voltage to converge the ions into acceleration region, and then the ions enter a field-free region. A cylindrical reflectron is used for focusing the ion beam and directing it back along the flight tube. When the ion beam reaches the detector, it is detected by a micro-channelplate detector. The electronic signal from the detector is sent to a time-to-digital converter (TDC) based data acquisition system. Mass spectrum histogram with 100 ps resolution is then passed to a laptop PC. Data analysis and processing including data reduction are performed using home-made data processing software.

The portable TOFMS employs a three-stage differential pumping system with an $80 \mathrm{~L} / \mathrm{s}$ split-flow turbomolecular pump and a $10 \mathrm{~L} / \mathrm{s}$ turbomolecular pump; both of the turbomolecular pumps are backed by a $5 \mathrm{~L} / \mathrm{min}$ diaphragm pump. The $10 \mathrm{~L} / \mathrm{s}$ turbomolecular pump is used for the first-stage differential pumping of ion source and held the pressure at $1.5 \mathrm{~Pa}$. The split-flow turbomolecular pump provides about $3 \mathrm{~L} / \mathrm{s}$ pumping for second stage of ion transmission region and $80 \mathrm{~L} / \mathrm{s}$ pumping for the third stage of mass analyzer (kept below $5 \times 10^{-4} \mathrm{~Pa}$ at working condition). Vacuum gauges (MKS 925) were used to monitor the pressure of ion source, and a MKS 972 vacuum gauge was used for mass analyzer. 


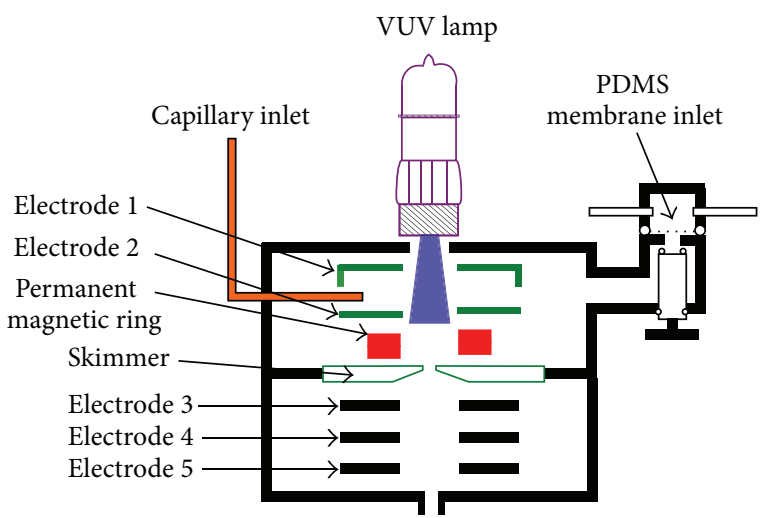

FIgURE 2: Configurations of the electrodes inside of the ion source and ion transmission region.

2.2. Sampling Inlet. The portable TOFMS is equipped with two kinds of sampling inlet: a fused silica capillary $(150 \mu \mathrm{m}$ in i.d., $1.7 \mathrm{~m}$ in length) based direct sampling inlet for high concentration analytes and a sheet PDMS membrane (with thickness of $50 \mu \mathrm{m}$ and $150 \mathrm{~mm}^{2}$ in area) inlet for trace analytes. A stainless steel mesh was set under the membrane to keep the sheet membrane flat. Volatile organic compounds (VOCs) in the sample diffuse faster than air when passing through the membrane into the ionization region; therefore, the VOCs are relatively enriched. The flow rate of the samples through the surface of the membrane was optimized as $1 \mathrm{~L} / \mathrm{min}$ and was controlled by a mass flow controller (Seven Star Electronics Co., Ltd., Beijing, China).

2.3. Ionization Source and Ion Transmission Region. The electrodes configuration inside of the ion source and ion transmission region is shown in Figure 2. The ionization source consists of three parts: a VUV lamp, permanent magnetic ring, and DC voltage lens including electrode 1 , electrode 2, and skimmer electrode. The VUV lamp is a commercial low-pressure krypton discharge lamp $(10.6 \mathrm{eV}$, Cathodeon Ltd., Cambridge, UK), with a flux of about $1 \times$ $10^{11}$ photons s $^{-1}$, and is installed on the top of ionization chamber. The VUV lamp was lighted by -1400 V DC voltages. The ion lens in the ion transmission region includes three cylinders: electrode 3, electrode 4, and electrode 5 . Electrode 1 , electrode 2, and skimmer are all tubular steel stainless electrodes; the size is $5.5 \mathrm{~mm}$ in length, $16 \mathrm{~mm}$ i.d., $28 \mathrm{~mm}$ o.d., and with $4 \mathrm{~mm}$ central hole $(1 \mathrm{~mm}$ central hole for skimmer electrode). These three electrodes are separated by insulator rings, and the distance from the VUV lamp light window to the surface of orifice electrode is only $20 \mathrm{~mm}$. The permanent magnetic ring locates between electrode 2 and skimmer, the dimensions were $31 \mathrm{~mm}$ in inner diameter, $19 \mathrm{~mm}$ in outer diameter, and $6.5 \mathrm{~mm}$ in thickness, and it offered a maximum energy product (BHmax) of $1200 \mathrm{~kJ} / \mathrm{m}^{3}$.

The ion transmission region consists of three circular electrodes with inner diameter of $10 \mathrm{~mm}$ and thickness of $2 \mathrm{~mm}, 1 \mathrm{~mm}$, and $2 \mathrm{~mm}$, respectively. The insulated spaces among the skimmer, electrode 3 , electrode 4 , and electrode 5 are all $2 \mathrm{~mm}$.
TABLE 1: Typical parameters of the portable time-of-flight mass spectrometer.

\begin{tabular}{lcc}
\hline Parameters & SPI mode & PEI mode \\
\hline Pressure inside of ion source & $1.25 \mathrm{~Pa}$ & $1.25 \mathrm{~Pa}$ \\
Electrode 1 & $20 \mathrm{~V}$ & $22.5 \mathrm{~V}$ \\
Electrode 2 & $17 \mathrm{~V}$ & $21 \mathrm{~V}$ \\
Skimmer & $5 \mathrm{~V}$ & $-45.5 \mathrm{~V}$ \\
Electrode 3 & $-20 \mathrm{~V}$ & $9 \mathrm{~V}$ \\
Electrode 4 & $-120 \mathrm{~V}$ & $-120 \mathrm{~V}$ \\
Electrode 5 & $40 \mathrm{~V}$ & $0 \mathrm{~V}$ \\
VUV lamp voltage & $-1400 \mathrm{~V}$ & $-1400 \mathrm{~V}$ \\
Repeller voltage & $400 \mathrm{~V}$ & $400 \mathrm{~V}$ \\
Accelerator & $1800 \mathrm{~V}$ & $1800 \mathrm{~V}$ \\
Reflector 1 & $1000 \mathrm{~V}$ & $1000 \mathrm{~V}$ \\
Reflector 2 & $420 \mathrm{~V}$ & $400 \mathrm{~V}$ \\
MCP detector & $2600 \mathrm{~V}$ & $2600 \mathrm{~V}$ \\
Pressure inside of mass analyzer & $5 \times 10^{-5} \mathrm{~Pa}$ & $5 \times 10^{-5} \mathrm{~Pa}$ \\
\hline
\end{tabular}

The ion source was operated at two modes: single photoionization (SPI) mode for analytes with ionization energy (IE) lower than $10.6 \mathrm{eV}$ and photoelectron ionization (PEI) mode for analytes with IE higher than $10.6 \mathrm{eV}$. The two different modes were controlled by the DC voltage applied on electrodes inside of ionization source. When $20 \mathrm{~V}, 17 \mathrm{~V}$, and $5 \mathrm{~V}$ were applied to electrode 1 , electrode 2 , and skimmer separately, the ionization source operates under SPI mode, and voltages on electrode 3 , electrode 4 , and electrode 5 were $-20 \mathrm{~V},-120$, and $40 \mathrm{~V}$. The PEI mode was originated from the electrons generated on the surface of skimmer by the photoelectric effect when VUV light irradiated on electrodes. The PEI mode was activated when voltages on electrode 1, electrode 2, and skimmer were changed to $22.5 \mathrm{~V}, 21 \mathrm{~V}$, and $-44.5 \mathrm{~V}$. The energy of the photoelectron was calculated as $67 \mathrm{eV}$ by subtracting the voltage on the skimmer from the voltage on electrode 1 , and the voltages on electrode 3 , electrode 4 , and electrode 5 were changed to $9 \mathrm{~V},-120$, and $0 \mathrm{~V}$, accordingly.

The total power consumption of the present ionization source was only $1.5 \mathrm{~W}$ with the VUV lamp, much lower than $50 \mathrm{~W}$ with traditional EI ionization source.

The mass analyzer of TOFMS consists of four parts: the ion repeller region, ion accelerator region, field-free region, and the reflectron with a length of $6 \mathrm{~mm}, 23 \mathrm{~mm}, 210 \mathrm{~mm}$, and $58 \mathrm{~mm}$, respectively. Typical parameters of the portable timeof-flight mass spectrometer were shown in Table 1 .

2.4. Methods Used for Gas Preparation. The two standard gas mixtures of $1 \mathrm{ppmV}$ benzene, toluene, and p-xylene (BTX) and 50 ppm $\mathrm{SO}_{2}$ diluted with $\mathrm{N}_{2}$ (99.9993\% purity) were purchased from Dalian Special Gas Company (Dalian, China). The samples of BTX and $\mathrm{SO}_{2}$ with different concentrations used in the experiments were obtained by diluting standard gas with pure $\mathrm{N}_{2}$ within a PTFE sampling bag. The dilution process was as follows: a measured amount of $\mathrm{N}_{2}$ was blown 

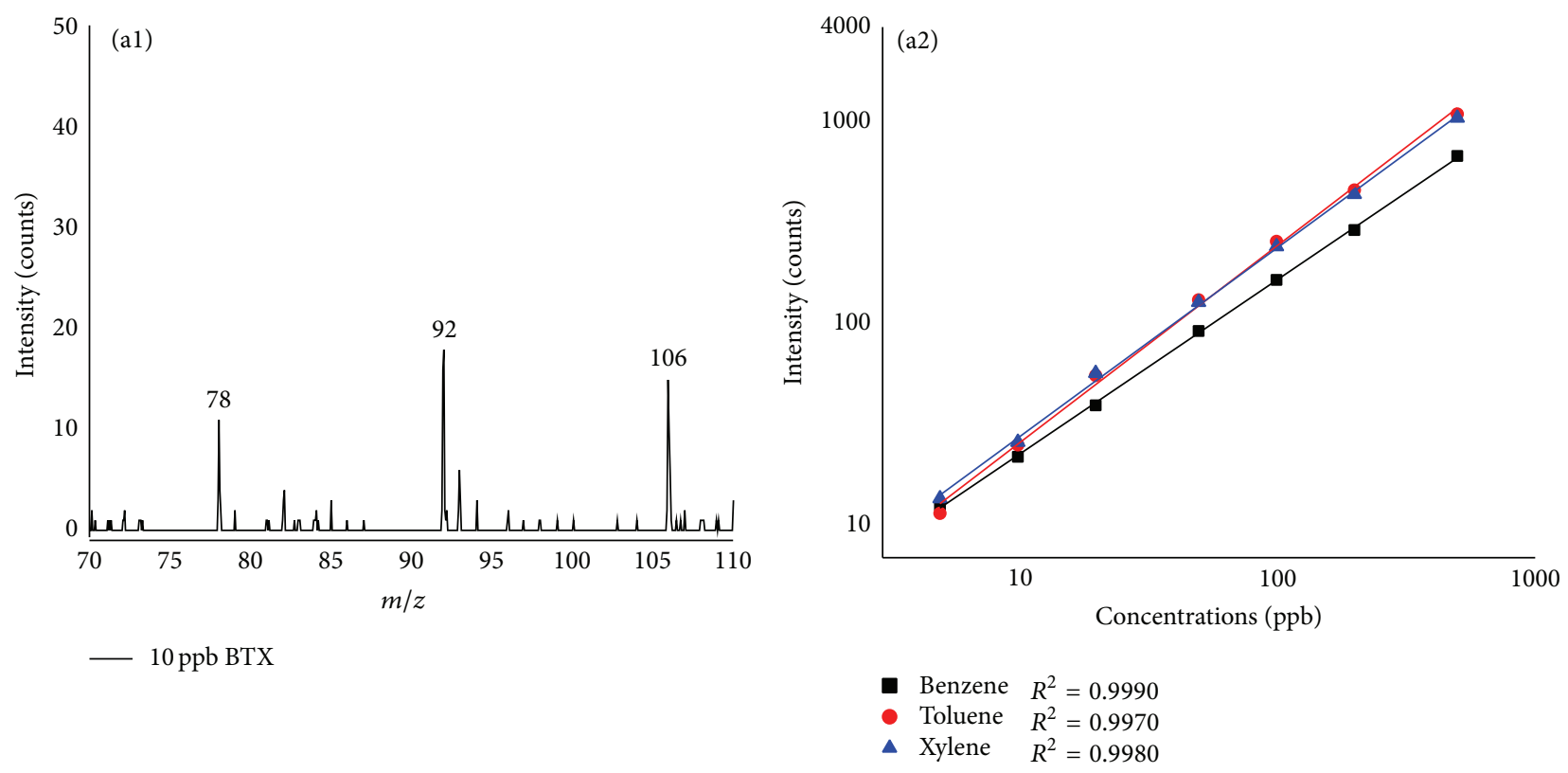

(a)
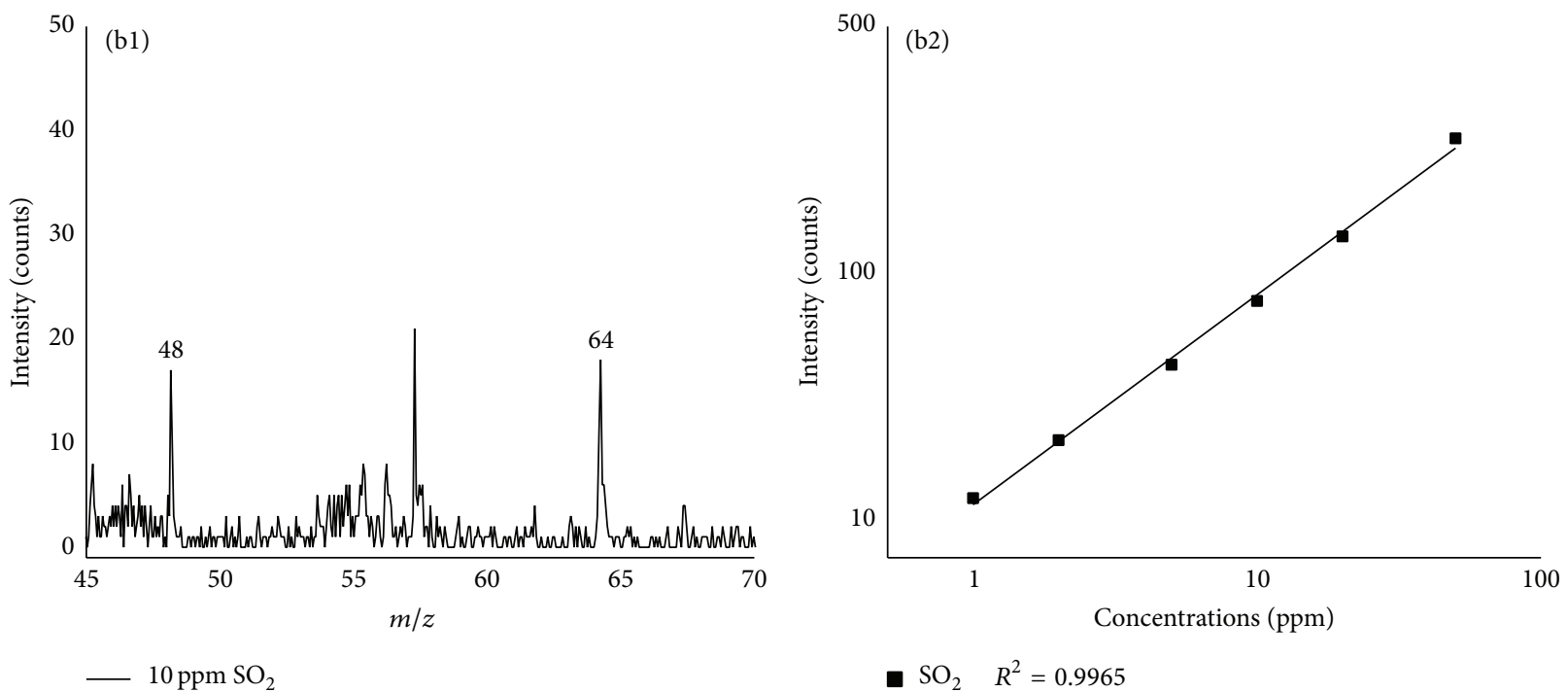

(b)

FIGURE 3: Spectra and the linear response curve for (a) benzene, toluene, and xylene and (b) $\mathrm{SO}_{2}$.

into a PTFE sampling bag, and then a desired amount of sample was added to the bag. The amount of $\mathrm{N}_{2}$ and sample was controlled by $3 \mathrm{~L} / \mathrm{min}$ and $100 \mathrm{~mL} / \mathrm{min}$ calibrated mass flow controllers.

\section{Performance of the Instrument}

The detection of $10 \mathrm{ppb}$ benzene, toluene, and xylene (BTX) was achieved in SPI mode with the membrane inlet. The spectra shown in Figure 3(a) were collected during $50 \mathrm{~s}$ at a repetition rate of $20 \mathrm{kHz}$. The linear response curve for of benzene, toluene, and xylene range is in the concentration range from $5 \mathrm{ppb}$ to $400 \mathrm{ppm}$, and the linear dynamic ranges are greater than four orders of magnitude with a good linear correlation coefficient $\left(R^{2}>0.9900\right)$. Based on the criteria of signal-to-noise ratio $(S / N=3)$, the limit of detection for BTX is calculated to be $1 \mathrm{ppbv}$. This sensitivity is even much better than the reported results in the literature with more powerful VUV light source [22].

$\mathrm{SO}_{2}$ can rarely be ionized in SPI mode for its high ionization energy $(12.5 \mathrm{eV})$; therefore, PEI mode was selected for its analysis. The concentrations of $\mathrm{SO}_{2}$ used in the experiment were $1 \mathrm{ppm}, 2 \mathrm{ppm}, 5 \mathrm{ppm}, 10 \mathrm{ppm}, 20 \mathrm{ppm}$, and $50 \mathrm{ppm}$, respectively. The samples were introduced to the TOFMS by the capillary inlet. The spectra were collected 


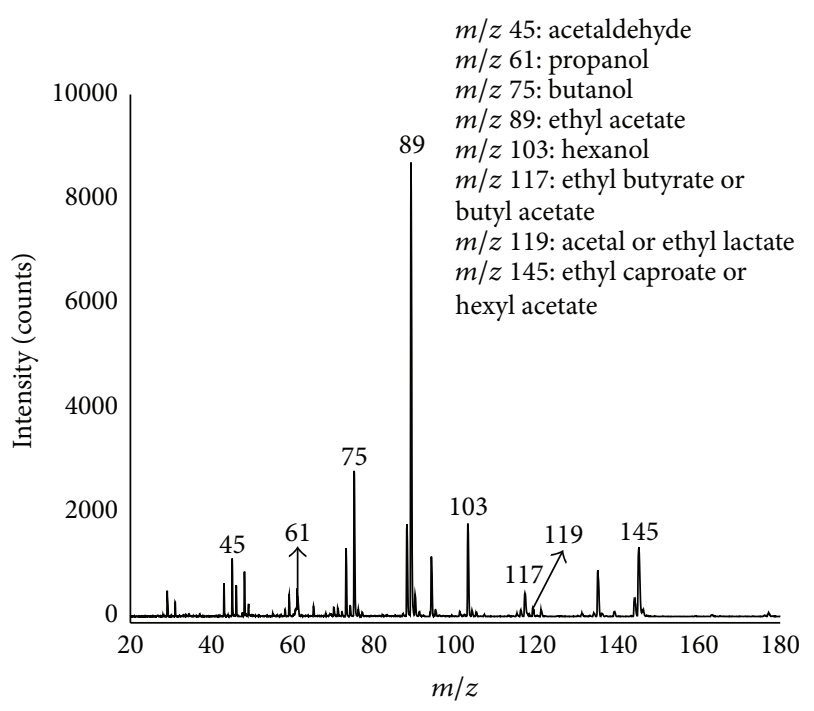

FIgURE 4: Spectrum of VOCs from wine with SPI TOFMS.

during $75 \mathrm{~s}$ at a repetition rate of $40 \mathrm{kHz}$. Figure 3(b) exhibits the mass spectrum and the linear response curve of $\mathrm{SO}_{2}$ for 6 different concentrations. The linear correlation coefficient was calculated as $0.9965\left(R^{2}=0.9965\right)$, and the limit of quantitation (LOQ) was determined as 1 ppm based on the criteria of $S / N=10: 1$.

The mass resolving power of the portable TOFMS, defined as $M / \Delta M$, where $M$ is the peak center and $\Delta M$ is the full-width half-maximum of the fitted Gaussian peak, was greater than 1100 at $64 \mathrm{~m} / z\left(\mathrm{SO}_{2}{ }^{+}\right)$. The obtained resolution is higher than the reported 500 resolutions with similar size of $53 \times 33 \times 21 \mathrm{~cm}$ [14]. In the laboratory, a mass resolving power of 1100 is routinely achieved for the range considered (10$300 \mathrm{Th}$ ). The stability of the portable TOFMS was investigated by comparing the tertian signal intensity of a $100 \mathrm{ppb}$ BTX, and the relative standard deviation (RSD) was less than $10 \%$.

\section{Applications}

4.1. Rapid Analysis of VOCs in Wine. Chinese wine contains lots of trace volatile organic compounds. The portable TOFMS analyzed the headspace compounds of the wine at room temperature. The capillary inlet was plugged directly into the headspace bottle. The spectrum of VOCs from wine with SPI ionization is shown in Figure 4, and the components were interpreted as acetaldehyde $\left(\mathrm{m} / z 44, \mathrm{C}_{2} \mathrm{H}_{4} \mathrm{O}\right)$, methanol $\left(\mathrm{m} / z\right.$ 32.04, $\left.\mathrm{CH}_{4} \mathrm{O}\right)$, n-propanol $\left(\mathrm{m} / z\right.$ 62.10, $\left.\mathrm{C}_{3} \mathrm{H}_{8} \mathrm{O}\right)$, nbutanol $\left(m / z\right.$ 74.12, $\left.\mathrm{C}_{4} \mathrm{H}_{10} \mathrm{O}\right)$, ethyl acetate $(\mathrm{m} / z$ 88.11, $\left.\mathrm{C}_{4} \mathrm{H}_{8} \mathrm{O}_{2}\right)$, pentanol $\left(m / z 88.15, \mathrm{C}_{5} \mathrm{H}_{12} \mathrm{O}\right)$, furfural $(\mathrm{m} / z$ 96.08, $\left.\mathrm{C}_{5} \mathrm{H}_{4} \mathrm{O}_{2}\right)$, hexanol $\left(\mathrm{m} / z 102.15, \mathrm{C}_{6} \mathrm{H}_{14} \mathrm{O}\right)$, ethyl butyrate $(\mathrm{m} / z$ $\left.116.16, \mathrm{C}_{6} \mathrm{H}_{12} \mathrm{O}_{2}\right)$, aldehyde acetal $\left(m / z 118.17, \mathrm{C}_{6} \mathrm{H}_{14} \mathrm{O}_{2}\right)$, ethyl lactate $\left(\mathrm{m} / z 118.13, \mathrm{C}_{5} \mathrm{H}_{10} \mathrm{O}_{3}\right)$, and ethyl hexanoate $(\mathrm{m} / z$ $\left.144.21, \mathrm{C}_{8} \mathrm{H}_{16} \mathrm{O}_{2}\right)$. The main characteristic compounds inside of the wine were all detected by the portable TOFMS. The peaks for wine obtained with VUV lamp are characteristic with $[\mathrm{M}-\mathrm{H}]^{+}$, which is quite different with $[\mathrm{M}+\mathrm{H}]^{+}$peaks by PTRMS [23].
TABLE 2: Physical properties and mass-to-charge ratios $(\mathrm{m} / \mathrm{z})$ of decomposition products from $\mathrm{SF}_{6}$.

\begin{tabular}{lccc}
\hline Compounds & IP (ev) & $M_{w}$ & Product ions \\
\hline $\mathrm{SF}_{6}$ & 15.30 & 146 & $127,108,89$ \\
$\mathrm{SOF}_{4}$ & 12.8 & 124 & 105 \\
$\mathrm{SiF}_{4}$ & 15.70 & 104 & 85 \\
$\mathrm{SO}_{2} F_{2}$ & 13.3 & 102 & 102 \\
$\mathrm{SOF}_{2}$ & 12.58 & 86 & 86 \\
$\mathrm{SO}_{2}$ & 12.35 & 64 & 64 \\
\hline
\end{tabular}

4.2. Discharging Products of Sulfur Hexafluoride $\left(S_{6}\right)_{6}$. Sulfur hexafluoride $\left(\mathrm{SF}_{6}\right)$ is widely used in gas-insulated switchgear (GIS) and transformers due to its excellent insulating and arcsuppression properties. However, in the presence of partial discharge, $\mathrm{SF}_{6}$ decomposes into various byproducts, which leads to a significant decrease in the electric property of $\mathrm{SF}_{6}$. These byproducts are often used to detect and identify partial discharge. For instance, $\mathrm{SO}_{2}, \mathrm{SOF}_{2}, \mathrm{SO}_{2} \mathrm{~F}_{2}, \mathrm{SF}_{4}, \mathrm{SOF}_{4}$, and $\mathrm{S}_{2} \mathrm{~F}_{10} \mathrm{O}$ could be present in $\mathrm{SF}_{6}$ insulating devices with discharging fault. The main characteristics of these discharging products were given in Table 2. All of these compounds have higher ionization energies than $10.6 \mathrm{eV}$. Therefore, PEI mode was selected for the analysis. The capillary inlet was used and the analysis time was $13 \mathrm{~s}$. The spectrum of the discharging products of $\mathrm{SF}_{6}$ is shown in Figure 5(a). Peaks of discharging products, $\mathrm{SO}_{2} \mathrm{~F}^{+}(m / z, 83), \mathrm{SiF}_{3}{ }^{+}(m / z, 85), \mathrm{SOF}_{2}{ }^{+}(m / z, 86)$, $\mathrm{SO}_{2} \mathrm{~F}_{2}{ }^{+}$or $\mathrm{S}_{2} \mathrm{~F}_{2}{ }^{+}(m / z, 102)$, and $\mathrm{SOF}_{3}{ }^{+}(m / z, 105)$, can be observed clearly in the figure. And the fragments and reaction products of $\mathrm{SF}_{6}$ such as $\mathrm{SF}^{+}(m / z, 51), \mathrm{OF}_{2}{ }^{+}(m / z, 54), \mathrm{SF}_{2}{ }^{+}$ $(m / z, 70), \mathrm{SF}_{5}{ }^{+}(m / z, 127), \mathrm{SF}_{4}{ }^{+}(m / z, 108)$, and $\mathrm{SF}_{3}{ }^{+}(m / z$, 89) can be observed as well. Peaks of $\mathrm{O}_{2}{ }^{+}(\mathrm{m} / z, 32)$ and $\mathrm{N}_{2}{ }^{+}(m / z, 28)$ can be observed due to the air mixed with $\mathrm{SF}_{6}$. The portable TOFMS was used for in situ detection of the real decomposition products of $\mathrm{SF}_{6}$ which were sampled from an insulation fault of a GIS. The spectrum is shown in Figure 5(b); the peaks of $m / z 64$ and $m / z 86$ can be ascribed to $\mathrm{SO}_{2}{ }^{+}$and $\mathrm{SOF}_{2}{ }^{+}$, which originate from gaseous byproducts of $\mathrm{SO}_{2}$ and $\mathrm{SOF}_{2}$, separately. The concentration of $\mathrm{SO}_{2}$ is calculated as $400 \mathrm{ppm}$ from the linear curve, and this result indicated that serious discharging has occurred inside the GIS.

\section{Conclusion}

A VUV lamp based portable TOFMS has been developed for field analysis of gas analytes. The portable TOFMS is equipped with two sampling inlets and dual ionization operating mode for different requirements. The TOFMS is $40 \times 31 \times 29 \mathrm{~cm}$ in size and $27 \mathrm{~kg}$ in weight with a favorable power consumption of $70 \mathrm{~W}$. Instrument performance was assessed using BTX and $\mathrm{SO}_{2}$, a mass resolution of 1100 at $\mathrm{m} / z$ 64 has been obtained, and, under optimized conditions, the detection limits for BTX were $0.005-400$ ppm by volume with linear dynamic ranges greater than four orders of magnitude. The portable TOFMS was used to detect $\mathrm{SO}_{2}$, the typical decomposition product of $\mathrm{SF}_{6}$, for diagnosis of potential 


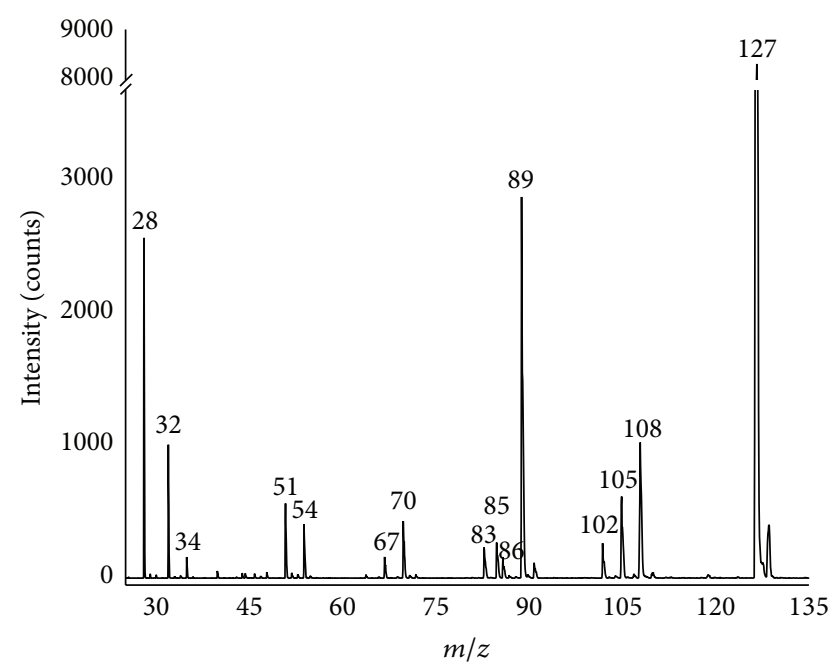

(a)

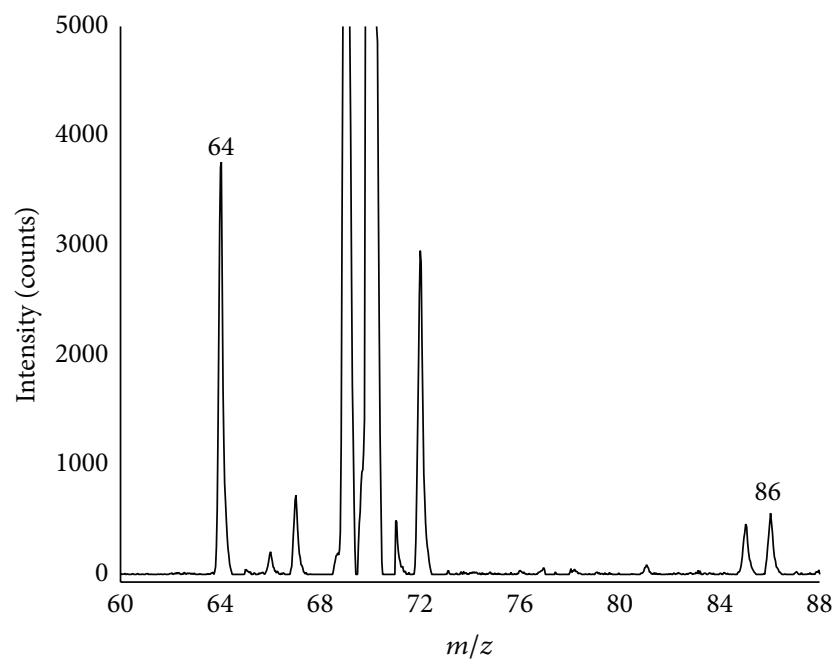

(b)

FIGURE 5: (a) Spectrum of the discharging products of $\mathrm{SF}_{6}$ with online PEI mass spectrometry and (b) spectrum of in situ detection of the real decomposition products of $\mathrm{SF}_{6}$.

fault in $\mathrm{SF}_{6}$-insulated switchgear. The results reported here indicate that compact, high-performance TOFMS is ready for field development.

\section{Conflict of Interests}

The authors declare that there is no conflict of interests regarding the publication of this paper.

\section{Acknowledgment}

The authors thank the financial support for this work by the Sciences Foundation of China Southern Power Grid (no. KGX2013-016).

\section{References}

[1] A. M. Llamas, C. B. Ojeda, and F. S. Rojas, "Process analytical chemistry-application of mass spectrometry in environmental analysis: an overview," Applied Spectroscopy Reviews, vol. 42, no. 4, pp. 345-367, 2007.

[2] S. A. Ecelberger, T. J. Cornish, B. F. Collins, D. L. Lewis, and W. A. Bryden, "Suitcase TOF: a man-portable time-of-flight mass spectrometer," Johns Hopkins APL Technical Digest, vol. 25, no. 1, pp. 14-19, 2004.

[3] S. Kumano, M. Sugiyama, M. Yamada et al., "Development of a portable mass spectrometer characterized by discontinuous sample gas introduction, a low-pressure dielectric barrier discharge ionization source, and a vacuumed headspace technique," Analytical Chemistry, vol. 85, no. 10, pp. 5033-5039, 2013.

[4] A. Malcolm, S. Wright, R. R. A. Syms, N. Dash, M.-A. Schwab, and A. Finlay, "Miniature mass spectrometer systems based on a microengineered quadrupole filter," Analytical Chemistry, vol. 82, no. 5, pp. 1751-1758, 2010.

[5] M. P. Sinha and M. Wadsworth, "Miniature focal plane mass spectrometer with 1000-pixel modified-CCD detector array for direct ion measurement," Review of Scientific Instruments, vol. 76, no. 2, Article ID 025103, 2005.
[6] T. Sikanen, S. Franssila, T. J. Kauppila, R. Kostiainen, T. Kotiaho, and R. A. Ketola, "Microchip technology in mass spectrometry," Mass Spectrometry Reviews, vol. 29, no. 3, pp. 351-391, 2010.

[7] A. Malcolm, S. Wright, R. R. A. Syms et al., "A miniature mass spectrometer for liquid chromatography applications," Rapid Communications in Mass Spectrometry, vol. 25, no. 21, pp. 32813288, 2011.

[8] M. Yang, T.-Y. Kim, H.-C. Hwang, S.-K. Yi, and D.-H. Kim, "Development of a palm portable mass spectrometer," Journal of the American Society for Mass Spectrometry, vol. 19, no. 10, pp. 1442-1448, 2008.

[9] R. J. Cotter, C. Fancher, and T. J. Cornish, "Miniaturized timeof-flight mass spectrometer for peptide and oligonucleotide analysis," Journal of Mass Spectrometry, vol. 34, no. 12, pp. 1368 1372, 1999.

[10] T. J. Cornish and R. J. Cotter, "A curved-field reflectron for improved energy focusing of product ions in time-of-flight mass spectrometry," Rapid Communcations in Mass Spctrometry, vol. 7, no. 11, pp. 1037-1040, 1993.

[11] S. A. Ecelberger, T. J. Cornish, B. F. Collins, D. L. Lewis, and W. A. Bryden, "Suitcase TOF: a man-portable time-of-flight mass spectrometer," Johns Hopkins APL Technical Digest, vol. 25, no. 1, pp. 14-19, 2004.

[12] T. J. Cornish and R. J. Cotter, "High-order kinetic energy focusing in an end cap reflectron time-of-flight mass spectrometer," Analytical Chemistry, vol. 69, no. 22, pp. 4615-4618, 1997.

[13] W. B. Brinckerhoff, T. J. Cornish, R. W. McEntire, A. F. Cheng, and R. C. Benson, "Miniature time-of-flight mass spectrometers for in situ composition studies," Acta Astronautica, vol. 52, no. 2-6, pp. 397-404, 2003.

[14] A. J. White, M. G. Blamire, C. A. Corlett et al., "Development of a portable time-of-flight membrane inlet mass spectrometer for environmental analysis," Review of Scientific Instruments, vol. 69, no. 1-2, pp. 565-571, 1998.

[15] J. A. Syage, M. A. Hanning-Lee, and K. A. Hanold, "A manportable, photoionization time-of-flight mass spectrometer," Field Analytical Chemistry and Technology, vol. 4, no. 4, pp. 204$215,2000$. 
[16] Q. Wu, L. Hua, K. Hou et al., "A combined single photon ionization and photoelectron ionization source for orthogonal acceleration time-of-flight mass spectrometer," International Journal of Mass Spectrometry, vol. 295, no. 1-2, pp. 60-64, 2010.

[17] L. Hua, Q. Wu, K. Hou et al., "Single photon ionization and chemical ionization combined ion source based on a vacuum ultraviolet lamp for orthogonal acceleration time-of-flight mass spectrometry," Analytical Chemistry, vol. 83, no. 13, pp. 53095316, 2011.

[18] K. Hou, J. Wang, and H. Li, "A new membrane inlet interface of a vacuum ultraviolet lamp ionization miniature mass spectrometer for on-line rapid measurement of volatile organic compounds in air," Rapid Communications in Mass Spectrometry, vol. 21, no. 22, pp. 3554-3560, 2007.

[19] P. Chen, K. Hou, L. Hua et al., "Quasi-trapping chemical ionization source based on a commercial VUV lamp for timeof-flight mass spectrometry," Analytical Chemistry, vol. 86, no. 3, pp. 1332-1336, 2014.

[20] W. Lindinger, A. Hansel, and A. Jordan, "Online monitoring of volatile organic compounds at pptv levels by means of proton-transfer-reaction mass spectrometry (PTR-MS): medical applications, food control and environmental research," International Journal of Mass Spectrometry and Ion Processes, vol. 173, no. 3, pp. 191-241, 1998.

[21] A. Jordan, S. Haidacher, G. Hanel et al., "An online ultra-high sensitivity proton-transfer-reaction mass-spectrometer combined with switchable reagent ion capability (PTR + SRI - MS)," International Journal of Mass Spectrometry, vol. 286, no. 1, pp. 32-38, 2009.

[22] F. Mühlberger, T. Streibel, J. Wieser, A. Ulrich, and R. Zimmermann, "Single photon ionization time-of-flight mass spectrometry with a pulsed electron beam pumped excimer VUV lamp for on-line gas analysis: setup and first results on cigarette smoke and human breath," Analytical Chemistry, vol. 77, no. 22, pp. 7408-7414, 2005.

[23] E. Boscaini, T. Mikoviny, A. Wisthaler, E. von Hartungen, and T. D. Märk, "Characterization of wine with PTR-MS," International Journal of Mass Spectrometry, vol. 239, no. 2-3, pp. 215219, 2004. 

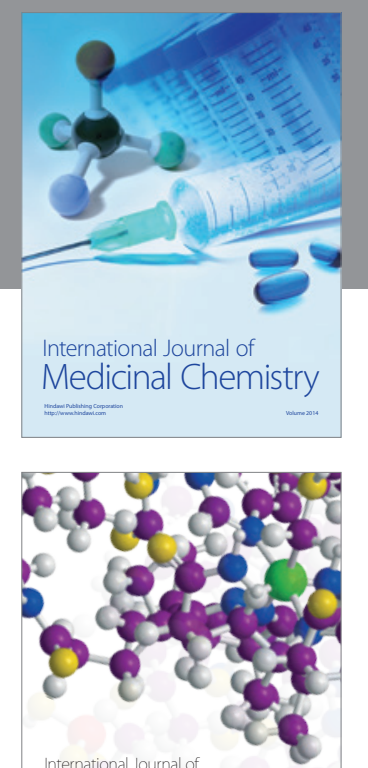

\section{Carbohydrate} Chemistry

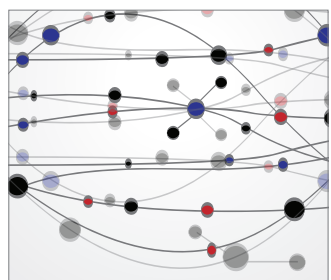

The Scientific World Journal



Submit your manuscripts at

http://www.hindawi.com

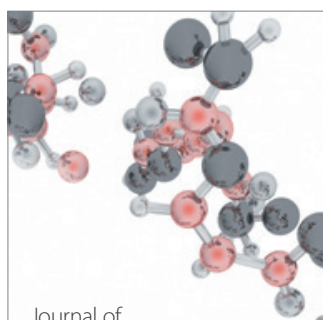

Analytical Methods

in Chemistry



Journal of

Applied Chemistry



Inorganic Chemistry
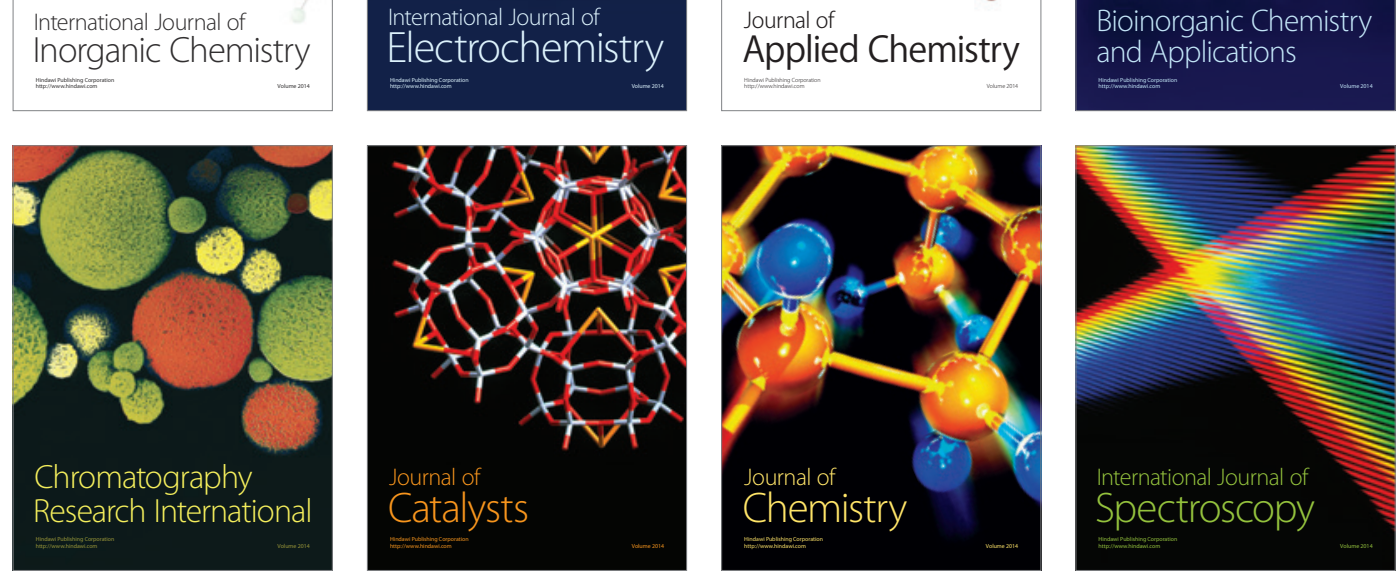